ఠ

\title{
A dermocosmetic containing bakuchiol, Ginkgo biloba extract and mannitol improves the efficacy of adapalene in patients with acne vulgaris: result from a controlled randomized trial
}

Katarína Poláková

Aurélie Fauger ${ }^{2}$

Michèle Sayag ${ }^{2}$

Eric Jourdan ${ }^{2}$

'Saint Elisabeth's Oncological Institute, Bratislava, Slovakia;

${ }^{2}$ Laboratoire Bioderma, Lyon, France
This article was published in the following Dove Press journal:

Clinical, Cosmetic and Investigational Dermatology

10 April 2015

Number of times this article has been viewed

Background: Acne vulgaris is an inflammatory disorder of the pilosebaceous unit.

Aim: To confirm that BGM (bakuchiol, Ginkgo biloba extract, and mannitol) complex increases the established clinical efficacy of adapalene $0.1 \%$ gel in patients with acne.

Methods: A clinical trial was conducted in acne patients. A total of 111 subjects received adapalene $0.1 \%$ gel and BGM complex or vehicle cream for 2 months. Assessments comprised Investigator Global Assessment (IGA), global efficacy, seborrhea intensity, inflammatory and non-inflammatory lesions, and subject perception, as well as overall safety and local tolerance and quality of life.

Results: At the end of the trial, inflammatory and non-inflammatory lesions, IGA, global efficacy, and seborrhea intensity had significantly improved in both treatment groups. Differences were statistically significant $(P<0.05)$ in favor of BGM complex for inflammatory lesions as well as IGA and seborrhea intensity. Global efficacy assessments and subject perception confirmed the superiority of BGM complex-including treatment over the comparative combination. Quality of life had improved more with the active combination than with the vehicle combination. In the active group, four subjects had to interrupt temporarily BGM complex and 12 adapalene compared to seven subjects interrupting the vehicle and eleven adapalene in the vehicle group. One subject withdrew from the trial due to an allergy to adapalene. The majority of all events were mild.

Conclusion: BGM complex improves the treatment outcome of adapalene $0.1 \%$ gel in patients with acne vulgaris. Overall, safety and local tolerance of BGM complex were good.

Keywords: adapalene, acne vulgaris, bakuchiol, BGM complex, P. acnes, sebum

\section{Introduction}

Acne vulgaris is a multifactorial, inflammatory disorder of the pilosebaceous unit. It presents with ductal hyperkeratinization and increased cohesiveness of keratinocytes, increased sebum production, alteration of sebum lipid composition, dysregulation of the hormone microenvironment, interaction with neuropeptides, hypercolonization by Propionibacterium acnes, and inflammation. ${ }^{1,2}$

Changes in the activity of the sebaceous gland not only result in seborrhea but also in alterations of the sebum fatty acid composition. ${ }^{3}$ Sebum lipid fractions with proinflammatory properties and inflammatory tissue cascades have been associated with the process of the development of acne lesions, while follicular keratinocytes and sebocytes, the major components of the pilosebaceous unit, act as immune-active
Correspondence: Eric Jourdan Laboratoire Bioderma, 75, cours Albert Thomas, 69447 Lyon Cedex 03, France Email e.jourdan@bioderma.com 
cells capable of microbial recognition and abnormal lipid presentation. ${ }^{4}$ The latter may be activated by $P$. acnes and recognize altered lipid content in sebum, followed by the production of proinflammatory cytokines.

There is no single topical antiacne medication that acts against all four major pathophysiologic acne features. Retinoids, such as adapalene, are well known for targeting comedones, including microcomedos and precursors of both inflammatory and non-inflammatory lesions, and exerting anti-inflammatory activity on the innate immunity. ${ }^{5-7}$ They are more and more often applied in combination with topical antibacterials, including antibiotics and benzoyl peroxide (BPO). ${ }^{8,9}$ The latter is known to cause irritation, while the use of topical antibiotics is less and less recommended due to the increased development of antimicrobial-resistant bacteria.

Laboratoire Bioderma, France, developed a new dermocosmetic cream containing a triple complex (hereafter BGM complex, Sébium Global cream). This complex mimics the effect of vitamin $\mathrm{E}$, allowing protection from potentially harmful effects of squalene oxidation products, such as hyperkeratinization and inflammation. ${ }^{10}$ The product contains a triple complex consisting of bakuchiol, Ginkgo biloba extract, and mannitol. ${ }^{1-14}$ Bakuchiol regulates seborrhea, is antibacterial, and has antiacne properties. ${ }^{15-19}$ In addition to its excipients, the active formulation contains enoxolone (18 $\beta$-glycyrrhetinic acid), salicylic acid, alpha hydroxy acid esters, and zinc gluconate, all of which are all well-recognized pharmacological active agents used in the treatment of acne..$^{20-23}$

The aim of the present trial was to assess the potential of BGM complex to improve the established clinical efficacy of adapalene $0.1 \%$ gel.

\section{Methods}

\section{Settings}

This multicenter and comparative double-blind clinical trial was conducted according to the Declaration of Helsinki of 1973 and all its amendments and its successive updates, to good clinical practices for the conduct of clinical trials and to local regulatory requirements. The trial was performed from January to June 2013 at 13 sites in Slovakia.

\section{Trial population}

Subjects had to be 12-25 years of age, present with mildto-moderate acne (grades 2-3 on the Investigator Global Assessment [IGA] scale), and had to be prescribed adapalene $0.1 \%$ gel for at least 2 months.

\section{Treatments}

Subjects were randomized at investigational sites in a $1: 1$ ratio to either an association of BGM complex cream and adapalene $0.1 \%$ gel, hereafter active association, or to an association of vehicle cream and adapalene (hereafter vehicle association).

Adapalene was prescribed by the investigators on the day of inclusion and had to be used as per the instructions.

BGM complex or the vehicle, containing water (aqua), glycerin, hydroxyethyl acrylate/sodium acryloyldimethyl taurate copolymer, isohexadecane, titanium dioxide, phenoxyethanol, chlorphenesin, polysorbate 60, alumina, and stearic acid, was to be applied on the entire face in the morning, after the face had been cleaned with a gentle cleanser. Adapalene was to be applied in the evening on the cleaned skin.

Make-up, except foundation cream, was permitted, while no other topical skin care product or treatment was authorized on the face during the trial. Oral contraception for women of childbearing potential had to remain unchanged during the course of the trial.

\section{Assessments}

Clinical evaluations of inflammatory and non-inflammatory lesions count, seborrhea intensity on a visual scale (from 0 : nil to 3: high), global acne severity using the IGA score (from 0: none to 4: severe), and global efficacy assessed on a scale (from 0 [lowest score] to 10 [highest possible score]) were performed on D0, D28, and D56 (D standing for day). Quality of life using the Cardiff Acne Disability Index ${ }^{24}$ was assessed on D0 and D56.

Safety was assessed through adverse event reporting; local tolerance signs and symptoms comprising erythema, desquamation, pruritus, burning, prickling, tightness, vesicles, papules, and edema were assessed on D28 and D56 by the investigator on a scale from 0 to $3(0=$ none, $1=$ light, $2=$ average, $3=$ high).

\section{Statistics}

Statistical analyses were performed on data from subjects who completed the trial. Quantitative criteria were expressed by sample size, mean, and standard deviation. Qualitative criteria were expressed in percentage. The Student's $t$-test on paired data or paired Wilcoxon test was applied to compare the number of non-inflammatory and inflammatory lesions, IGA and intensity of seborrhea between D0 and D28, and D0 and D56 in each group. Differences between groups for lesion count, intensity of seborrhea and IGA were calculated using 
the Student's $t$-test or Mann-Whitney test. The chi-square test was used to compare global efficacy between groups. A two-sided significance level of 0.05 was chosen. IGA was compared between each time point.

\section{Results}

\section{Demographics and baseline data}

A total of 111 subjects participated in this trial, 55 in the active association and 56 in the vehicle association group (Table 1). Three patients presented with an acne severity of less than mild (IGA grade 1) at inclusion. The investigator decided to maintain these subjects in the trial.

\section{Efficacy \\ Lesion count}

After 56 days of treatment, the mean number of non-inflammatory lesions had decreased from $34.4 \pm 23.5$ to $15.2 \pm 13.5$ lesions in the active association group and from $29.3 \pm 20.3$ to $14.6 \pm 8.5$ lesions in the vehicle association group. The percent decrease at D56 from D0 reached 56\% and 50.2\% in the active association and the vehicle association groups, respectively (Figure 1A). These reductions were statistically significant $(P<0.005)$ for each group and sustained from D28. The difference between both groups was not statistically significant.

At D56 compared to D0, the mean number of inflammatory lesions had decreased in both groups: from $18.4 \pm 10.9$ to $6.9 \pm 6.6$ and from $17.3 \pm 11.5$ to $10.1 \pm 10.4$ lesions in the active association and vehicle association groups, respectively. At the end of the trial, the percent decrease from D0 was $62.7 \%$ for the active association group and $41.5 \%$ for the vehicle association group (Figure 1B). These reductions were statis-

Table I Demographics and baseline data

\begin{tabular}{lll}
\hline & $\begin{array}{l}\text { Active } \\
\text { association }\end{array}$ & $\begin{array}{l}\text { Vehicle } \\
\text { association }\end{array}$ \\
\hline $\begin{array}{l}\text { Number of subjects } \\
\text { Age (years) }\end{array}$ & 55 & 56 \\
$\quad \begin{array}{l}\text { Mean } \pm \text { SD } \\
\text { Min/max }\end{array}$ & $18.7 \pm 3.4$ & $18.7 \pm 3.0$ \\
Sex & $13 / 25$ & $12 / 25$ \\
$\quad$ Male & $17(30.9 \%)$ & $16(28.6 \%)$ \\
$\quad$ Female & $38(69.1 \%)$ & $40(71.4 \%)$ \\
Acne severity & & \\
$\quad$ Almost none & $1(1.8 \%)$ & $2(3.7 \%)$ \\
$\quad$ Mild & $25(45.4 \%)$ & $33(58.9 \%)$ \\
$\quad$ Moderate & $28(50.9 \%)$ & $18(32.1 \%)$ \\
$\quad$ Severe & $1(1.8 \%)$ & $3(5.3 \%)$ \\
Seborrhea intensity score & $2.1 \pm 0.6$ & $1.8 \pm 0.6$ \\
IGA & $2.5 \pm 0.6$ & $2.3 \pm 0.6$ \\
\hline
\end{tabular}

Abbreviation: IGA, Investigator Global Assessment.
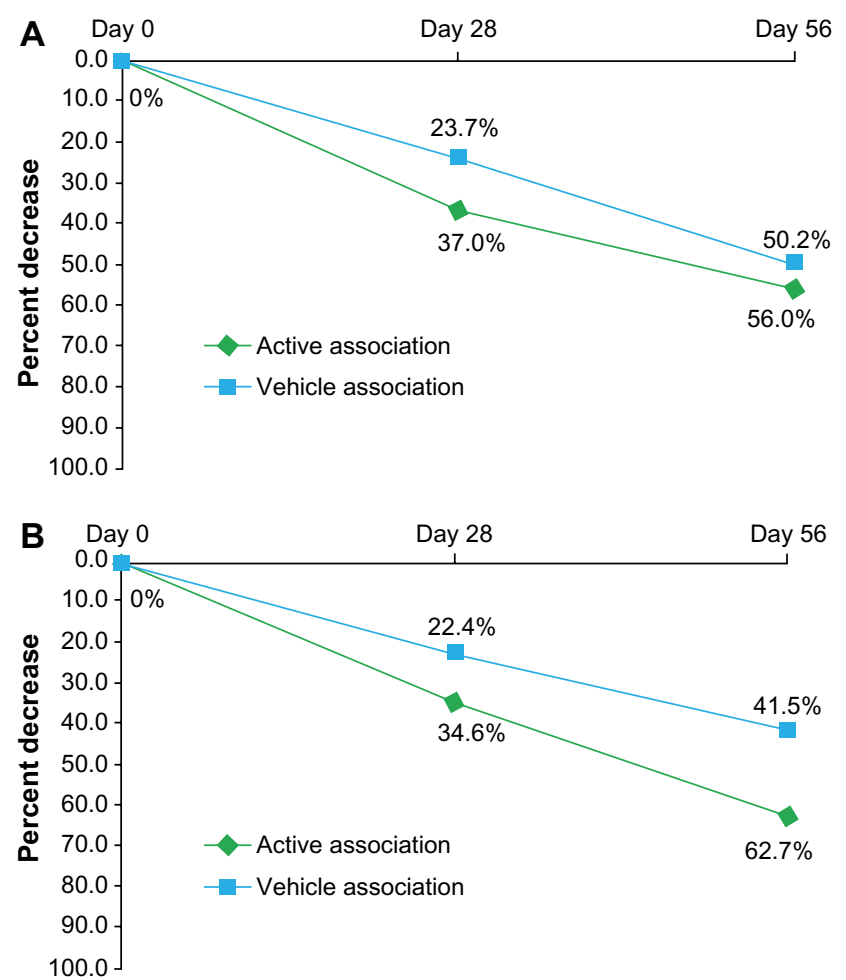

Figure I Percent decrease over time of acne lesions: (A) non-inflammatory and (B) inflammatory lesions.

Notes: At D56, the difference to D0 was statistically significant $(P<0.005)$ for both groups. The between-treatment group difference was not significant for noninflammatory lesions, while it was significant for inflammatory lesions $(P<0.05)$. Abbreviation: D, day.

tically significant $(P<0.005)$ and sustained from D28. The difference between both groups was statistically significant $(P<0.05)$ and in favor of the active association group.

Table 2 shows results for seborrhea intensity, IGA, global efficacy evaluation, and quality of life at D0 and D56.

\section{Safety}

In the active association group, 23 subjects reported at least one local adverse event (burning sensation, erythema, desquamation, and pruritus). In 15 subjects, they were considered related to adapalene and in four subjects, related to BGM complex. The majority of all local adverse events were mild in intensity.

A total of 12 subjects had to stop adapalene and four had to stop BGM complex. The interruption of applications was temporary in all subjects except for one subject who experienced an allergy considered to be related to adapalene.

In the vehicle association group, 17 subjects reported at least one local adverse event (erythema, burning sensation, pruritus, and desquamation). Of those, 12 were related to adapalene. The majority of all local adverse events were mild in intensity. 
Table 2 Results for seborrhea intensity, IGA, global efficacy evaluation, and quality of life after 56 days of use of BGM complex or vehicle in combination with adapalene $0.1 \%$ gel

\begin{tabular}{|c|c|c|c|c|c|}
\hline \multirow[t]{2}{*}{ Criterion } & \multicolumn{2}{|c|}{ Active association } & \multicolumn{2}{|c|}{ Vehicle association } & \multirow{2}{*}{$\begin{array}{l}\text { P-value } \\
\text { (between groups) }\end{array}$} \\
\hline & Do & D56 & Do & D56 & \\
\hline Seborrhea intensity & $2.1 \pm 0.6$ & $1.0 \pm 0.6(-51.9 \%)$ & $1.8 \pm 0.6$ & $1.3 \pm 0.6(-26.4 \%)$ & $P<0.005^{*}$ \\
\hline IGA & $2.5 \pm 0.6$ & $1.5 \pm 0.6(-40.3 \%)$ & $2.3 \pm 0.6$ & $1.7 \pm 0.8(-26.9)$ & $P<0.0 I^{*}$ \\
\hline \multicolumn{6}{|c|}{ Global efficacy evaluation } \\
\hline \multicolumn{6}{|c|}{ Investigator } \\
\hline Cleared & & $8.2 \%$ & & $4.1 \%$ & $P<0.05^{*}$ \\
\hline Improved & & $91.8 \%$ & & $75.5 \%$ & \\
\hline \multicolumn{6}{|l|}{ Subject } \\
\hline Cleared & & $18.4 \%$ & & $2 \%$ & $P<0.05^{*}$ \\
\hline Improved & & $75.5 \%$ & & $77.6 \%$ & \\
\hline Quality of life & $4.9 \pm 2.6$ & $2.3 \pm 2.0(-54 \%)$ & $4.7 \pm 2.3$ & $3.2 \pm 2.8(-31.2 \%)$ & $P<0.005^{*}$ \\
\hline
\end{tabular}

Note: *P-values in favor of the active association

Abbreviations: BGM, bakuchiol, Ginkgo biloba extract, and mannitol; D, day; IGA, Investigator Global Assessment.

In eleven subjects, adapalene had to be interrupted temporarily; vehicle had to be interrupted temporarily in seven subjects.

\section{Discussion and conclusion}

After 2 months of combined use with adapalene, BGM complex improved significantly the clinical outcome for inflammatory lesions when compared to the vehicle. The fact that BGM complex enhances the anti-inflammatory potential of adapalene may be due to its antibacterial properties on P. acnes as well as its anti-irritation potential. Results observed for the non-inflammatory and inflammatory lesion counts were confirmed by the IGA, the seborrhea intensity, and the global efficacy rated by the investigator and the subject, which at the end of the trial were all significantly in favor of the BGM complex/adapalene regimen; quality of life of subjects had significantly improved. Even though results are not shown, the excellent subjects' perceptions of BGM complex may have contributed to making them adhere to their treatment, especially in the light of acne being a chronic disease. ${ }^{25}$ One may argue that subjective evaluation is secondary to objective clinical assessments. However, disfigurement from inflamed lesions, post-inflammatory hyperpigmentation, and scars often causes embarrassment and frequently undermines confidence and lowers self-esteem. Hence, adherence to treatment, reducing sequels from acne is crucial for a positive treatment outcome.

The fact that bakuchiol, one of BGM complex agents, has antibacterial properties may open new perspectives in the issue of $P$. acnes strains, becoming more and more resistant to antibiotics. Indeed, to limit the use of topical antibiotics, retinoids such as adapalene are more and more combined with BPO. However, BPO may cause irritation and is hence contraindicated in a certain number of patients. As for BPO, bakuchiol does not lead to antibiotic resistance. Hence, in such patients, BGM complex may be considered an alternative to BPO. To confirm this, future clinical trials may be conducted to evaluate the efficacy of BGM complex combined to a topical retinoid compared to a combination of topical retinoids and topical antibacterials.

A similar number of subjects reported mild and transient local adverse events with BGM complex and with the vehicle cream; the majority of local adverse events were caused by adapalene, even though known to be the less-irritating topical retinoid. ${ }^{26,27}$

A missing treatment arm with adapalene in monotherapy and the short treatment duration, treatment of adapalene should last 3 months, may raise concerns for limitations. However, we feel that the results obtained from the active and the vehicle groups confirmed the expected treatment outcome of adapalene. Therefore, we consider that the trial is robust enough to show that BGM complex improves the treatment outcome of adapalene in patients with acne vulgaris.

In conclusion, the dermocosmetic containing BGM complex improves the treatment outcome of adapalene in patients with acne vulgaris and is well tolerated.

\section{Acknowledgments}

The authors acknowledge the contribution of the investigators and staff members of the trial centers, the scientific advice provided by Prof Dr Christos C Zouboulis, Germany, and the writing support provided by Patrick Göritz, SMWS Scientific and Medical Writing Services, France. The trial was funded by Laboratoire Bioderma, France. 


\section{Disclosure}

Dr Katarína Poláková has no financial interest to disclose. Eric Jourdan, Aurélie Fauger, and Michèle Sayag are employees of Laboratoire Bioderma, France.

\section{References}

1. Zouboulis CC, Eady A, Philpott M, et al. What is the pathogenesis of acne? Exp Dermatol. 2005;14(2):143-152.

2. Kurokawa I, Danby FW, Ju Q, et al. New developments in our understanding of acne pathogenesis and treatment. Exp Dermatol. 2009; 18(10):821-832.

3. Zouboulis CC, Jourdan E, Picardo M. Acne is an inflammatory disease and alterations of sebum composition initiate acne lesions. J Eur Acad Dermatol Venereol. 2014;28(5):527-532.

4. Koreck A, Pivarcsi A, Dobozy A, Kemeny L. The role of innate immunity in the pathogenesis of acne. Dermatology. 2003;206(2):96-105.

5. Leyden J. Adapalene in clinical practice. Cutis. 2001;68(4 Suppl): 7-9.

6. Bershad S, Poulin YP, Berson DS, et al. Topical retinoids in the treatment of acne vulgaris. Cutis. 1999;64(2 Suppl):8-20. [quiz 21-23].

7. Thielitz A, Sidou F, Gollnick H. Control of microcomedone formation throughout a maintenance treatment with adapalene gel, 0.1\%. J Eur Acad Dermatol Venereol. 2007;21(6):747-753.

8. Babaeinejad SH, Fouladi RF. The efficacy, safety and tolerability of adapalene versus benzoyl peroxide in the treatment of mild acne vulgaris; a randomized trial. J Drugs Dermatol. 2013;12(9): 1033-1038.

9. Bettoli V, Borghi A, Zauli S, et al. Maintenance therapy for acne vulgaris: efficacy of a 12-month treatment with adapalene-benzoyl peroxide after oral isotretinoin and a review of the literature. Dermatology. 2013;227(2):97-102.

10. Chiba K, Yoshizawa K, Makino I, Kawakami K, Onoue M. Comedogenicity of squalene monohydroperoxide in the skin after topical application. J Toxicol Sci. 2000;25(2):77-83.

11. Feng $\mathrm{X}$, Zhang L, Zhu H. Comparative anticancer and antioxidant activities of different ingredients of Ginkgo biloba extract (EGb 761). Planta Med. 2009;75(8):792-796.

12. Liu JH, Chen MM, Huang JW, et al. Therapeutic effects and mechanisms of action of mannitol during $\mathrm{H}_{2} \mathrm{O}_{2}$-induced oxidative stress in human retinal pigment epithelium cells. J Ocul Pharmacol Ther. 2010;26(3): 249-257.

13. Goldie M, Dolan S. Bilobalide, a unique constituent of Ginkgo biloba, inhibits inflammatory pain in rats. Behav Pharmacol. 2013;24(4): 298-306.
14. Cavone L, Calosi L, Cinci L, Moroni F, Chiarugi A. Topical mannitol reduces inflammatory edema in a rat model of arthritis. Pharmacology. 2012;89(1-2):18-21.

15. Kaul R. In vitro Kinetik der anti-Staphylococcus Aktivität von Bakuciol. [Kinetics of the anti-staphylococcal activity of bakuchiol in vitro (author's trans1)]. Arzneimittelforschung. 1976;26(4):486-489. German.

16. Katsura H, Tsukiyama RI, Suzuki A, Kobayashi M. In vitro antimicrobial activities of bakuchiol against oral microorganisms. Antimicrob Agents Chemother. 2001;45(11):3009-3013.

17. Ferrándiz ML, Gil B, Sanz MJ, et al. Effect of bakuchiol on leukocyte functions and some inflammatory responses in mice. J Pharm Pharmacol. 1996;48(9):975-980.

18. Pae HO, Cho H, Oh GS, et al. Bakuchiol from Psoralea corylifolia inhibits the expression of inducible nitric oxide synthase gene via the inactivation of nuclear transcription factor-kappaB in RAW 264.7 macrophages. Int Immunopharmacol. 2001;1(9-10):1849-1855.

19. Chaudhuri RK, Bojanowski K. Bakuchiol: a retinol-like functional compound revealed by gene expression profiling and clinically proven to have anti-aging effects. Int J Cosmet Sci. 2014;36(3):221-230.

20. Messerschmidt A, Schultheis K, Ochsendorf F. Topische Benhandlung von Infektionen, Tumoren und Hyperkeratosen. [Topical treatment of infections, tumors and hyperkeratotic disorders]. Hautarzt. 2014; 65(3):207-217. German.

21. Poiraud C, Quereux G, Knol AC, Allix R, Khammari A, Dreno B. Zinc gluconate is an agonist of peroxisome proliferator-activated receptoralpha in the epidermis. Exp Dermatol. 2012;21(5):347-351.

22. Loden M. Role of topical emollients and moisturizers in the treatment of dry skin barrier disorders. Am J Clin Dermatol. 2003;4(11):771-788.

23. Ishida T, Mizushina Y, Yagi S, et al. Inhibitory effects of glycyrrhetinic acid on DNA polymerase and inflammatory activities. Evid Based Complement Alternat Med. 2012;2012:650514.

24. Motley RJ, Finlay AY. Practical use of a disability index in the routine management of acne. Clin Exp Dermatol. 1992;17(1):1-3.

25. Zouboulis CC. Acne as a chronic systemic disease. Clin Dermatol. 2014;32(3):389-396.

26. Dosik JS, Homer K, Arsonnaud S. Cumulative irritation potential of adapalene $0.1 \%$ cream and gel compared with tretinoin microsphere 0.04\% and 0.1\%. Cutis. 2005;75(4):238-243.

27. Dosik JS, Homer K, Arsonnaud S. Cumulative irritation potential of adapalene $0.1 \%$ cream and gel compared with tazarotene cream $0.05 \%$ and $0.1 \%$. Cutis. 2005;75(5):289-293.
Clinical, Cosmetic and Investigational Dermatology

\section{Publish your work in this journal}

Clinical, Cosmetic and Investigational Dermatology is an international, peer-reviewed, open access, online journal that focuses on the latest clinical and experimental research in all aspects of skin disease and cosmetic interventions. All areas of dermatology will be covered; contributions will be welcomed from all clinicians and

\section{Dovepress}

basic science researchers globally. This journal is indexed on CAS. The manuscript management system is completely online and includes a very quick and fair peer-review system, which is all easy to use. Visit http://www.dovepress.com/testimonials.php to read real quotes from published authors. 